Article

\title{
A New Real Time Lyapunov Based Controller for Power Quality Improvement in Unified Power Flow Controllers Using Direct Matrix Converters
}

\author{
Joaquim Monteiro ${ }^{1, *}$, Sónia Pinto ${ }^{2}$, Aranzazu Delgado Martin ${ }^{3}$ and José Fernando Silva ${ }^{2}$ \\ 1 INESC-ID, 1000-029 Lisbon, Portugal, and Instituto Superior de Engenharia de Lisboa, \\ Polytechnic Institute of Lisbon, 1959-007 Lisbon, Portugal \\ 2 INESC-ID, 1000-029 Lisbon, Portugal, and with DEEC, Instituto Superior Técnico, University of Lisbon, \\ 1049-001 Lisbon, Portugal; soniafp@tecnico.ulisboa.pt (S.P.); fernando.alves@tecnico.ulisboa.pt (J.F.S.) \\ 3 Electrical Engineering Department, University of Huelva, La Rábida, 21819 Palos de la Frontera, Spain; \\ aranzazu.delgado@die.uhu.es \\ * Correspondence: jmonteiro@deea.isel.ipl.pt; Tel.: +351-218-317-000
}

Academic Editor: Frede Blaabjerg

Received: 17 March 2017; Accepted: 1 June 2017; Published: 6 June 2017

\begin{abstract}
This paper proposes a Direct Matrix Converter operating as a Unified Power Flow Controller (DMC-UPFC) with an advanced control method for UPFC, based on the Lyapunov direct method, presenting good results in power quality assessment. This control method is used for real-time calculation of the appropriate matrix switching state, determining which switching state should be applied in the following sampling period. The control strategy takes into account active and reactive power flow references to choose the vector converter closest to the optimum. Theoretical principles for this new real-time vector modulation and control applied to the DMC-UPFC with input filter are established. The method needs DMC-UPFC dynamic equations to be solved just once in each control cycle, to find the required optimum vector, in contrast to similar control methods that need 27 vector estimations per control cycle. The designed controller's performance was evaluated using Matlab/Simulink software. Controllers were also implemented using a digital signal processing (DSP) system and matrix hardware. Simulation and experimental results show decoupled transmission line active $(P)$ and reactive $(Q)$ power control with zero theoretical error tracking and fast response. Output currents and voltages show small ripple and low harmonic content.
\end{abstract}

Keywords: Unified Power Flow Controllers (UPFC); Direct Matrix Converter (DMC); digital control; real time Lyapunov

\section{Introduction}

Direct matrix converters (DMCs) are alternative power converters to DC-link back-to-back connected inverter-rectifier with capacitive energy storage. Therefore, DMCs can be advantageously used in unified power flow controllers (UPFCs). UPFCs emerged in the 1990s by L. Gyugyi as the most versatile FACTS (Flexible AC Transmission Systems) equipment [1,2]. FACTS technology uses power electronic devices-namely power semiconductors-with turn-off capability associated to their firing circuits and modern control techniques to enforce the active and reactive power in electrical systems. These power controllers work in real time to regulate the energy transit in the transmission lines up to its thermal limits [3].

The UPFC with a classic topology, based on two AC-DC converters back to back connected through a common DC link, needs a large high-voltage DC storage capacitor bank to allow shunt and series compensation and bidirectional power flow [4-6]. The UPFC controls some line parameters 
(such as impedance, bus voltage, voltage angle) guaranteeing fast, dynamic performance of the power transmission network and ensuring a reliable and precise control of both line active, $P$, and reactive, $Q$, power flow [6-8].

Several research works with UPFC show conventional control methods based on power systems with linearized models, valid around an operating point, whose dynamic control and performance evaluation are presented in [9-12]. However, these control methods present poor dynamic responses and/or undesired active-reactive power coupling. Improved approaches are based on nonlinear controllers, allowing a better tuning of linear controller parameters, and have the capability to adapt to the continuously changing power system dynamics [13-15]. In [14], nonlinear robust direct power controllers allow dynamic response improvement based on sliding mode control techniques to select adequate space vectors to control active and reactive power in real time.

In recent years, alternative UPFC topologies have emerged based on the direct three phase AC-AC matrix converter [11-16]. This power converter eliminates the DC link capacitors, thus reducing cost, size, and maintenance, while increasing reliability and lifetime. The DMC processes electrical energy directly needing almost no energy storage, allows bidirectional power flow, guarantees near sinusoidal input and output currents, and controls the voltage's amplitude and frequency at an adjustable power factor $[17,18]$. These AC/AC converters guarantee that the active power exchanged on the UPFC series connection is always supplied/absorbed by the shunt connection, and still have the capability to allow independent reactive control on the UPFC shunt and series converter sides. However, as there is almost no DMC stored energy, input and output powers are strongly coupled, hardening the control design.

The main contribution of this paper is, therefore, a new real-time vector modulation and control for the DMC-UPFC. This control method uses an algorithm based on the power system model equations and the direct method (2nd method) of Lyapunov to guarantee asymptotic stability. The control strategy is based on the desired references for active, $P$, and reactive, $Q$, power flow and uses a cost functional to choose the converter output vector closest to the optimum [19] considering $P$ and $Q$ requirements. The power controllers choose the converter output vector by minimizing the distance between the virtual control vector and all available converter vectors. This digital control method allows a significant reduction in the computing time of the digital signal processing (DSP) unit in many industrial applications [20].

A theoretical analysis of the new real time Lyapunov-based controller, applied to the DMC-UPFC with input filter, is presented (Section 3). Dynamic and steady-state performance of the $P$ and $Q$ power control method is evaluated and discussed using detailed simulations and experimental implementation (Sections 4 and 5). Results show a controller insensitive to power system non-linearity and active and reactive power control with zero error tracking and fast response times (Section 6). Results also show a low total harmonic distortion (THD) in the output voltages and currents ensuring a good performance of this controller in power quality applications. The controllers are insensitive to power system non-linearity, presenting very low sensitivity to cross-coupling effects.

\section{Modeling of the UPFC Power System}

The proposed power system model of the DMC operating as a UPFC is presented in the simplified scheme of Figure 1.

In this power transmission network, $V_{S}$ and $V_{R}$ are the sending-end and receiving-end voltages, respectively, of $G_{S}$ and $G_{R}$ generators feeding load $Z_{\text {load }}$. The DMC is connected to the transmission line 2 through shunt and series coupling transformers, respectively $T_{1}$ and $T_{2}$. Also, as shown in Figure $1, Z_{L 1}$ and $Z_{L 2}$ are the impedances of the transmission lines 1 and 2, respectively, represented as a series inductance and resistance. 


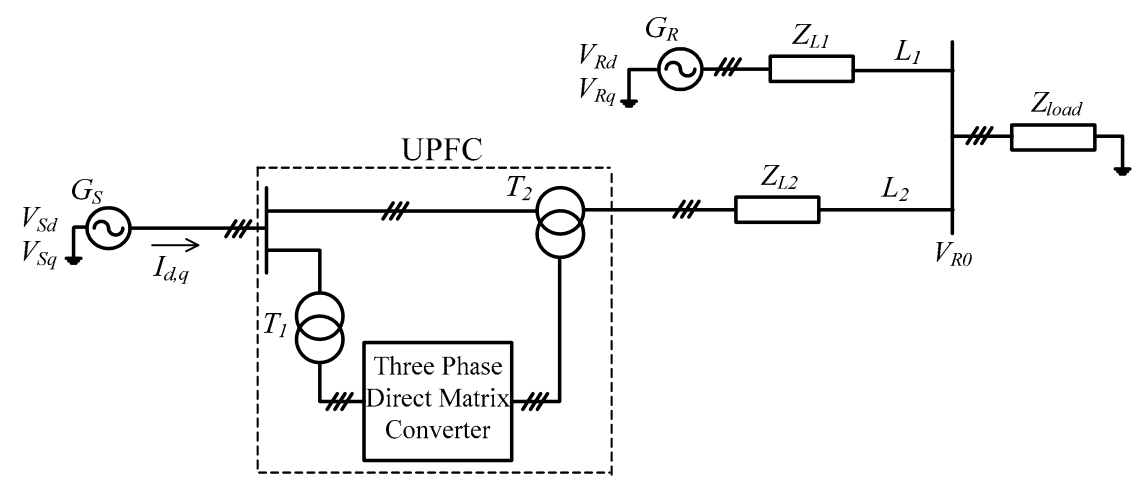

Figure 1. Transmission network with DMC-UPFC.

\subsection{UPFC Power System Dynamic Model}

Figure 2 shows the connection diagram of the DMC-UPFC system to the transmission line. This diagram includes a three-phase $L C R$ input low pass filter to re-establish a voltage-source boundary to the DMC input and to enable smoother input currents. A three-phase shunt input transformer $\left(T_{a}\right.$, $\left.T_{b}, T_{c}\right)$, a three-phase series output transformer $\left(T_{A}, T_{B}, T_{C}\right)$ and a three-phase DMC are also included.

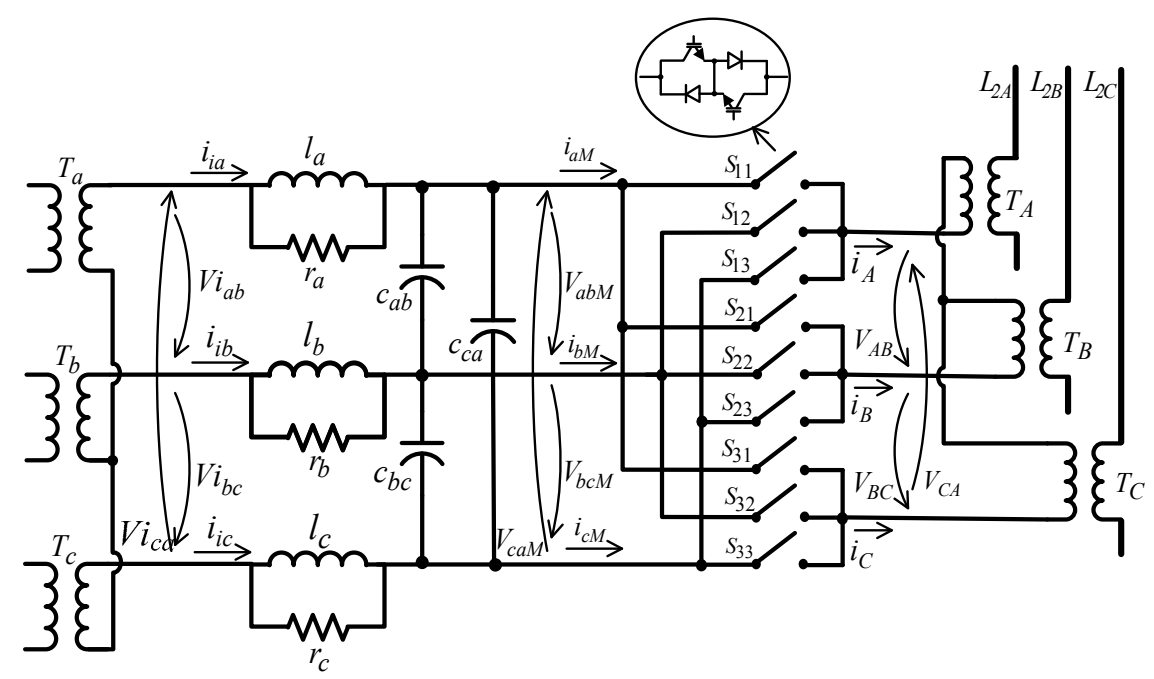

Figure 2. A detailed diagram with DMC-UPFC.

To design DMC-UPFC decoupled active and reactive power controllers, the dynamic Equation (1) is considered. This equation represents the active and reactive power of sending end generator $G_{S}$, in $d q$ coordinates [21].

$$
\left[\begin{array}{l}
P \\
Q
\end{array}\right]=\left[\begin{array}{cc}
V_{S d} & V_{S q} \\
V_{S q} & -V_{S d}
\end{array}\right]\left[\begin{array}{c}
I_{d} \\
I_{q}
\end{array}\right]
$$

where $V_{S d}, V_{S q}$ are the mains voltage components, and $I_{d}, I_{q}$ the line currents, both in $d q$ coordinates (Figure 1).

Choosing a $d q$ rotating reference frame so that the mains voltage $\left(V_{S q}\right)$ is equal to zero, $P$ and $Q$ will be given by Equation (2).

$$
\left[\begin{array}{c}
P \\
Q
\end{array}\right]=\left[\begin{array}{c}
V_{S d} I_{d} \\
-V_{S d} I_{q}
\end{array}\right]
$$

The control vector components to ensure convergence of the power references values are obtained considering the time derivative of Equation (3), assuming constant $V_{S d}$. 


$$
\frac{d}{d t}\left[\begin{array}{l}
P \\
Q
\end{array}\right]=V_{S d} \frac{d}{d t}\left[\begin{array}{c}
I_{d} \\
-I_{q}
\end{array}\right]
$$

Considering a symmetrical and balanced three-phase system, an equivalent per-phase model of a DMC-UPFC transmission system, shown in Figure 3, is obtained, where the voltage sources, the coupling transformers and the DMC are all considered ideal. Based on this simplified circuit, the dynamics of three-phase currents $i j$ in the transmission line is:

$$
\frac{d i_{j}}{d t}=\frac{V_{S j}+V_{C j}-R_{2} i_{j}-V_{R 0 j}}{L_{2}}, \quad j=1,2,3
$$

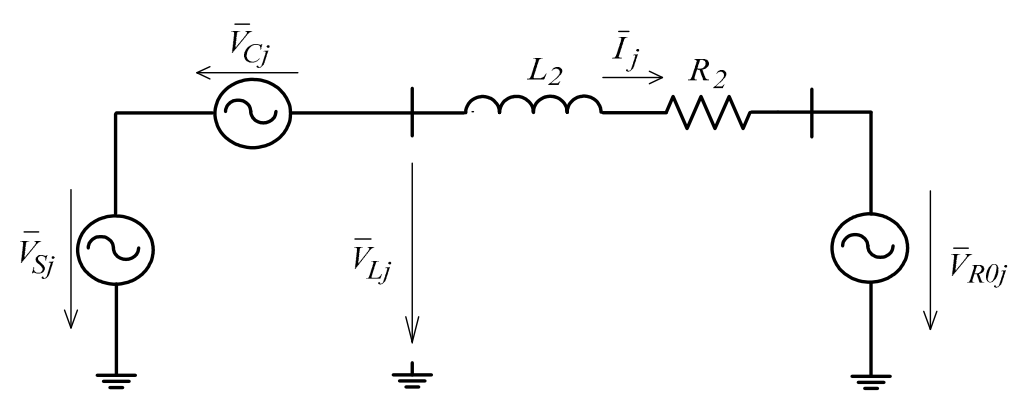

Figure 3. Equivalent per-phase circuit of DMC-UPFC transmission system.

Applying the Kirchhoff laws to the equivalent circuit gives the equations of the AC line currents in $d q$ coordinates:

$$
\frac{d}{d t}\left[\begin{array}{c}
I_{d} \\
I_{q}
\end{array}\right]=\left[\begin{array}{cc}
-\frac{R_{2}}{L_{2}} & \omega \\
-\omega & -\frac{R_{2}}{L_{2}}
\end{array}\right]\left[\begin{array}{c}
I_{d} \\
I_{q}
\end{array}\right]+\frac{1}{L_{2}}\left[\begin{array}{c}
V_{S d}+V_{C d}-V_{R 0 d} \\
+V_{C q}-V_{R 0 q}
\end{array}\right]
$$

In (5), Thevenin equivalent inductance and resistance $\left(L_{2}\right.$ and $\left.R_{2}\right)$ are estimated by $L_{2}=X_{2} / \omega$, $R_{2}=R_{L 2}+R_{L 1}|| R_{\text {Zload }}$.

Substituting line currents (5) in (3) and simplifying the result, Equation (6) is obtained:

$$
\frac{d}{d t}\left[\begin{array}{l}
P \\
Q
\end{array}\right]=\left[\begin{array}{cc}
-\frac{R_{2}}{L_{2}} & -\omega \\
\omega & -\frac{R_{2}}{L_{2}}
\end{array}\right]\left[\begin{array}{l}
P \\
Q
\end{array}\right]+\frac{V_{S d}}{L_{2}}\left[\begin{array}{c}
V_{S d}+V_{C d}-V_{R 0 d} \\
V_{C q}-V_{R 0 q}
\end{array}\right]
$$

From these dynamics, it can be seen that $P$ and $Q$ can be controlled by $V_{C d}$ and $V_{C q}$, being $V_{R 0 d}$ and $V_{R 0 q}$ system disturbances.

\subsection{Direct Matrix Converter Model}

To apply a closed-loop space-vector technique, the ideal three-phase direct matrix converter may be considered as an array of nine bi-directional switches, $S_{k j}$. These switches have turn-on and turn-off capability, allowing the connection of each one of three output phases directly to a given three-phase input voltage.

Considering also ideal power semiconductors, each DMC bi-directional switch $S_{k j}(k, j \in\{1,2,3\})$ can assume two possible states: " $S_{k j}=1$ " (switch closed) or " $S_{k j}=0$ " (switch opened), being the nine DMC switches represented as a $3 \times 3$ matrix (7). Taking into account circuit topology restrictions, no input phase short-circuits and no open output phases, there are only 27 possible switching combinations [14].

$$
\left[\begin{array}{lll}
S_{11} & S_{12} & S_{13} \\
S_{21} & S_{22} & S_{23} \\
S_{31} & S_{32} & S_{33}
\end{array}\right] \sum_{j=1}^{3} S_{k j}=1 \quad k, j \in\{1,2,3\}
$$


According to Figure 2 the output and input voltages are related by matrix $S$, being $\left[\begin{array}{lll}v_{A} & v_{B} & v_{C}\end{array}\right]^{T}=S\left[\begin{array}{lll}v_{a} & v_{b} & v_{c}\end{array}\right]^{T}$. Then, it is necessary to represent the output voltages and the input currents yielding 27 switching patterns, as time variant vectors in $\alpha \beta$ coordinates [14]. The relationship between input phase currents and output phase currents depends on the transposition of matrix $S:\left[\begin{array}{lll}i_{a} & i_{b} & i_{c}\end{array}\right]^{T}=S^{T}\left[\begin{array}{lll}i_{A} & i_{B} & i_{C}\end{array}\right]^{T}$.

\section{DMC-UPFC Lyapunov-Based Control}

The proposed control strategy based on the direct method of Lyapunov stability starts by defining a positive definite Lyapunov candidate function $V_{X}=e_{X}^{2} / 2$, where $e_{X}$ is the tracking error of the $X$ variable, $e_{X}=X_{\text {Ref }}-X$. To ensure a globally asymptotically-stable control solution from Lyapunov's direct method of stability [22], the time derivative $\dot{V}_{X}$ of the positive-definite Lyapunov function $V_{X}$ must be globally negative-definite $\dot{V}_{X}<0$, or $e_{X} \dot{e}_{X}<0$. This can be achieved by imposing an error dynamic such as:

$$
\dot{e}_{X}+k_{X} e_{X}=0 \Rightarrow \dot{e}_{X}=-k_{X} e_{X}
$$

where $k_{X}$ is a positive definite constant, resulting in $e_{X} \dot{e}_{X}=-k_{X} e_{X}^{2}<0$. Equation (8) ensures asymptotic stability, as the $e_{X}$ error tends to zero with time constant $1 / k_{X}$, and robustness as the error dynamic in (8) is independent of the system parameters.

\subsection{Active and Reactive Power Control}

The control objective is to track the power references $P_{\text {Ref }}, Q_{\text {Ref }}$, so that $e_{X}=\left[e_{P}, e_{Q}\right]^{T}$, the tracking errors (or deviations) being $e_{P}=P_{\text {Ref }}-P$ and $e_{Q}=Q_{\text {Ref }}-Q$ :

$$
\left[\begin{array}{c}
e_{P} \\
e_{Q}
\end{array}\right]=\left[\begin{array}{c}
P_{\operatorname{Ref}}-P \\
Q_{\operatorname{Ref}}-Q
\end{array}\right] \approx\left[\begin{array}{l}
0 \\
0
\end{array}\right]
$$

To guarantee no cross-coupling between $P$ and $Q$ power controllers, fast response times and asymptotic stability, Lyapunov candidate functions are defined as $V_{P}=e_{P}{ }^{2} / 2, V_{Q}=e_{Q}^{2} / 2$. Therefore, the controller must enforce:

$$
\left[\begin{array}{cc}
e_{P} & 0 \\
0 & e_{Q}
\end{array}\right] \frac{d}{d t}\left[\begin{array}{l}
e_{P} \\
e_{Q}
\end{array}\right]<\left[\begin{array}{l}
0 \\
0
\end{array}\right]
$$

This can be accomplished if it is considered:

$$
\frac{d}{d t}\left[\begin{array}{c}
e_{P} \\
e_{Q}
\end{array}\right]=-\left[\begin{array}{cc}
k_{P} & 0 \\
0 & k_{Q}
\end{array}\right]\left[\begin{array}{l}
e_{P} \\
e_{Q}
\end{array}\right]=-\left[\begin{array}{cc}
k_{P} & 0 \\
0 & k_{Q}
\end{array}\right]\left[\begin{array}{c}
P_{\operatorname{Ref}}-P \\
Q_{\operatorname{Ref}}-Q
\end{array}\right]
$$

where $k_{P}, k_{Q}$ are positive definite constants. Replacing the $e_{P}, e_{Q}$ time derivates using (6), Equation (12) is received:

$$
\frac{d}{d t}\left[\begin{array}{c}
P_{\text {Ref }} \\
Q_{\text {Ref }}
\end{array}\right]-\left[\begin{array}{cc}
-\frac{R_{2}}{L_{2}} & -\omega \\
\omega & -\frac{R_{2}}{L_{2}}
\end{array}\right]\left[\begin{array}{c}
P \\
Q
\end{array}\right]-\frac{V_{S d}}{L_{2}}\left[\begin{array}{c}
V_{S d}+V_{C d \operatorname{Ref}}-V_{R 0 d} \\
-V_{C q \operatorname{Ref}}+V_{R 0 q}
\end{array}\right]=-\left[\begin{array}{cc}
k_{P} & 0 \\
0 & k_{Q}
\end{array}\right]\left[\begin{array}{c}
P_{\text {Ref }}-P \\
Q_{\text {Ref }}-Q
\end{array}\right]
$$

Solving Equation (12) for $V_{C d \text { Ref }}$ and $V_{C q \text { Ref }}$ the DMC controller must impose the output voltages $V_{C d \text { Ref }}$ and $V_{C q \text { Ref }}$.

$$
\begin{gathered}
{\left[\begin{array}{c}
V_{C d \text { Ref }} \\
V_{C q \text { Ref }}
\end{array}\right]=\frac{L_{2}}{V_{S d}}\left(\left[\begin{array}{cc}
k_{P} & 0 \\
0 & -k_{Q}
\end{array}\right]\left[\begin{array}{c}
P_{\text {Ref }}-P \\
Q_{\text {Ref }}-Q
\end{array}\right]+\frac{d}{d t}\left[\begin{array}{c}
P_{\text {Ref }} \\
-Q_{\text {Ref }}
\end{array}\right]\right)} \\
+\frac{1}{V_{S d}}\left[\begin{array}{cc}
R_{2} & \omega L_{2} \\
-\omega L_{2} & R_{2}
\end{array}\right]\left[\begin{array}{c}
P \\
Q
\end{array}\right]-\left[\begin{array}{c}
V_{S d}-V_{R 0 d} \\
-V_{R 0 q}
\end{array}\right]
\end{gathered}
$$


This equation defines the reference values $V_{C d \text { Ref }}, V_{C q \text { Ref }}$ that must be injected in the line by the series transformer of the space-vector PWM controlled DMC.

\subsection{Input Reactive Power Control}

Applying Blondel-Park transformation to the input filter state variables presented in Figure 3 and neglecting the effects of the damping resistors, Equation (14) can be written, where $V_{i d}, V_{i q}, i_{i d}, i_{i q}$ represent input voltages and input currents in $d q$ components (at the shunt transformer secondary), and $V_{d M}, V_{q M}, i_{d M}, i_{q M}$ are DMC voltages and input currents in $d q$ components, respectively,

$$
\left\{\begin{array}{l}
\frac{d i_{i d}}{d t}=\omega i_{i q}-\frac{1}{2 l} V_{d M}-\frac{1}{2 \sqrt{3} l} V_{q M}+\frac{1}{l} V_{i d} \\
\frac{d i_{i q}}{d t}=-\omega i_{i d}+\frac{1}{2 \sqrt{3} l} V_{d M}-\frac{1}{2 l} V_{q M}+\frac{1}{l} V_{i q} \\
\frac{d V_{d M}}{d t}=\omega V_{q M}-\frac{1}{2 \sqrt{3} C} i_{i q}+\frac{1}{2 C} i_{i d}-\frac{1}{2 C} i_{d M}+\frac{1}{2 \sqrt{3} C} i_{q M} \\
\frac{d V_{q M}}{d t}=-\omega V_{d M}+\frac{1}{2 \sqrt{3} C} i_{i d}+\frac{1}{2 C} i_{i q}-\frac{1}{2 \sqrt{3} C} i_{d M}-\frac{1}{2 C} i_{q M}
\end{array}\right.
$$

This transformation guarantees all input variables of the matrix converter are time invariant in the rotating reference frame.

The control objective is to have $Q_{i}=Q_{i \text { Ref }}=0$. The control input is $i_{q M}$ and the output is $i_{i q}$, as $Q_{i}=-V_{i d} i_{i q}$ at constant $V_{i d}$. Defining the tracking error $e_{Q i}=Q_{i \operatorname{Ref}}-Q_{i}=-Q_{i}$, to guarantee Lyapunov asymptotic stability in this 2nd order system, the controller must enforce an exponentially stable error dynamics tending to zero such as $\ddot{e}_{Q i}+k_{1} \dot{e}_{Q i}+k_{2} e_{Q i}=0$, where $k_{1}$ and $k_{2}$ are positive definite constants. Therefore:

$$
\begin{aligned}
& \frac{d^{2} e_{Q_{i}}}{d t^{2}}+k_{1} \frac{d e_{Q_{i}}}{d t}+k_{2} e_{Q_{i}}=0 \Rightarrow \frac{d^{2} Q_{i R e f}}{d t^{2}}-\frac{d^{2} Q_{i}}{d t^{2}}+k_{1} \frac{d e_{Q_{i}}}{d t}+k_{2} e_{Q_{i}}=0 \Rightarrow \\
& \frac{d^{2} Q_{i \operatorname{Ref}}}{d t^{2}}+k_{1} \frac{d e_{Q_{i}}}{d t}+k_{2} e_{Q_{i}}=\frac{d^{2} Q_{i}}{d t^{2}}
\end{aligned}
$$

Solving (14) for $\frac{d^{2} Q_{i}}{d t^{2}}$, Equation (16) is obtained:

$$
\begin{aligned}
& \frac{d^{2} Q_{i}}{d t^{2}}=\frac{d}{d t}\left[\frac{d\left(-V_{i d} i_{i q}\right)}{d t}\right]=-V_{i d} \frac{d}{d t}\left[\frac{d}{d t} i_{i q}\right]=-V_{i d} \frac{d}{d t}\left(-\omega i_{i d}+\frac{1}{2 \sqrt{3} l} V_{d M}-\frac{1}{2 l} V_{q M}+\frac{1}{l} V_{i q}\right) \Rightarrow \\
& \frac{d^{2} Q_{i}}{d t^{2}}=-V_{i d}\left(-\omega \frac{d i_{i d}}{d t}+\frac{1}{2 \sqrt{3} l} \frac{d V_{d M}}{d t}-\frac{1}{2 l} \frac{d V_{q M}}{d t}+\frac{1}{l} \frac{d V_{i q}}{d t}\right)
\end{aligned}
$$

Simplifying (16) and replacing the value of $\frac{d^{2} Q_{i}}{d t^{2}}$ in (15), Equation (17) is obtained:

$$
\begin{aligned}
& \frac{1}{V_{i d}} \frac{d^{2} Q_{i \operatorname{Ref}}}{d t^{2}}+\frac{k_{1}}{V_{i d}} \frac{d e_{Q_{i}}}{d t}+\frac{k_{2}}{V_{i d}} e_{Q_{i}}= \\
& \left(\omega^{2}+\frac{1}{3 l C}\right) i_{i q}-\frac{\omega}{l} V_{d M}-\frac{\omega}{\sqrt{3} l} V_{q M}+\frac{\omega}{l} V_{i d}-\frac{1}{3 l C} i_{q M \operatorname{Ref}}-\frac{1}{l} \frac{d V_{i q}}{d t}
\end{aligned}
$$

where $i_{q M \text { Ref }}$ is the value of $i_{q M}$ (control input) that satisfies (15). Solving (17) for the reference value $i_{q M \text { Ref }}$ of the $q$ component of the matrix current $i_{q M}$, Equation (18) is obtained:

$$
\begin{aligned}
i_{q M \operatorname{Ref}}= & \frac{3 l C}{V_{i d}}\left(\frac{d^{2} Q_{i \operatorname{Ref}}}{d t^{2}}+k_{1} \frac{d e_{Q_{i}}}{d t}+k_{2} e_{Q_{i}}\right)+\left(3 l C \omega^{2}+1\right) i_{i q}+ \\
& 3 C \omega\left(V_{i d}-V_{d M}\right)-\sqrt{3} C \omega V_{q M}-3 C \frac{d V_{i q}}{d t}
\end{aligned}
$$


Equations (13) and (18) require distinct space-vectors to impose $V_{C d \text { Ref }}, V_{C q \text { Ref }}$ and $i_{q M R e f}$, as discussed in Section 2.2. The optimum space-vector is computed in the next section by minimizing a cost functional of the reference voltages and current errors.

\subsection{Optimum Space-Vector}

A weighted cost functional of squared tracking errors is used to select in real time the optimum space-vector (one out of the 27 possible switching combinations) which should be applied to the DMC operated as UPFC in the following sampling period.

The vector selection strategy minimizes the cost functional given in (19).

$$
C\left(t_{s}\right)=\sqrt{G_{V_{C d}} e_{V_{C d}}^{2}+G_{V_{C q}} e_{V_{C q}}^{2}+G_{I_{i q}} e_{i_{q M}}^{2}}
$$

where $e_{V_{C d}}=V_{C d \text { Ref }}-V_{C d v}, e_{V_{C q}}=V_{C q \text { Ref }}-V_{C q v}$ and $e_{i_{q M}}=i_{q M \operatorname{Ref}}-i_{q M v}$, represent the errors between the references and values obtained with each switching combination, and $G_{V_{C d^{\prime}}} G_{V_{C q}}$ and $G_{I_{q M}}$ are the respective weights.

In each sampling time $t_{s}$, the real-time modulation control method first calculates the reference components, $V_{C d \operatorname{Ref}}\left(t_{s}\right), V_{C q \operatorname{Ref}}\left(t_{s}\right)$ and $i_{q M \operatorname{Ref}}\left(t_{s}\right)$ given in (13) and (18). Then, the weighted cost functional (19) is evaluated for each one of the 27 matrix vectors to select the one presenting the minimum value of the cost functional.

\section{Implementation of DMC-UPFC Controller}

The implementation scheme of the proposed DMC-UPFC controller is presented in the block diagram of Figure 4. In this scheme, the control of the instantaneous $P$ and $Q$ powers requires the measurement of the instantaneous output voltages and currents. The control of the matrix input reactive power requires the measurement of the input currents, and the measurement of the mains and capacitor voltages.

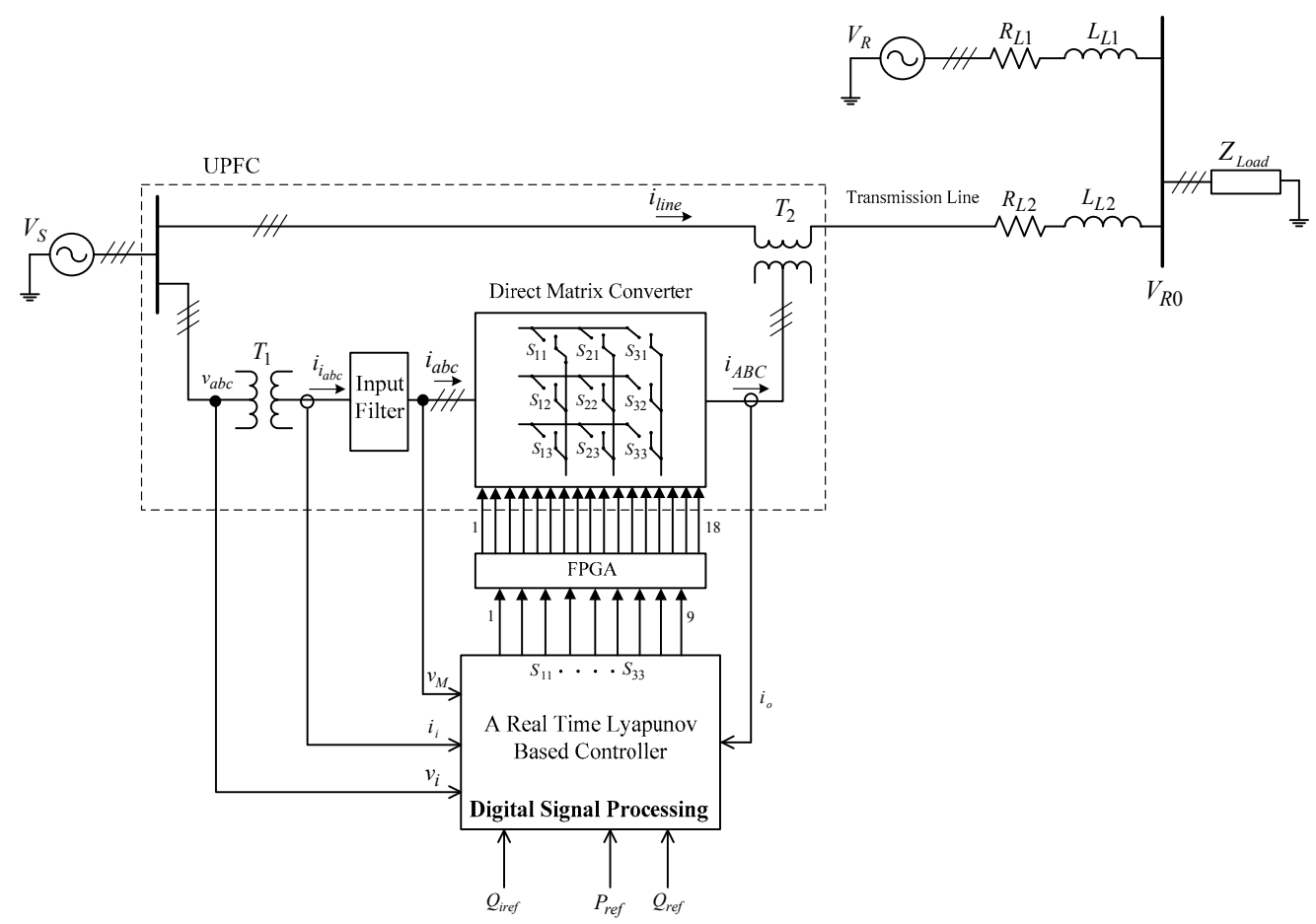

Figure 4. Control scheme of the real time Lyapunov-based controller of the DMC-UPFC. 
The real time Lyapunov-based controller (Figure 4) algorithm, implemented in a digital signal processor, is presented in the flowchart in Figure 5. As shown in the diagram, the control method main loop calculates the values of $V_{C d \text { Ref }}\left(t_{s}\right), V_{C q \operatorname{Ref}}\left(t_{s}\right)$ and $i_{q M \text { Ref }}\left(t_{s}\right)$ once, while the cost functional, $C\left(t_{s}\right)$, is evaluated 27 times to find the vector with components $V_{C d}\left(t_{s}\right), V_{C q}\left(t_{s}\right)$ and $i_{q M}\left(t_{s}\right)$ that minimizes the weighted cost functional. This selects the space-vector which minimizes the cost functional, and is applied to the DMC-UPFC in the following sampling time $\left(t_{s}+\Delta T\right)$.

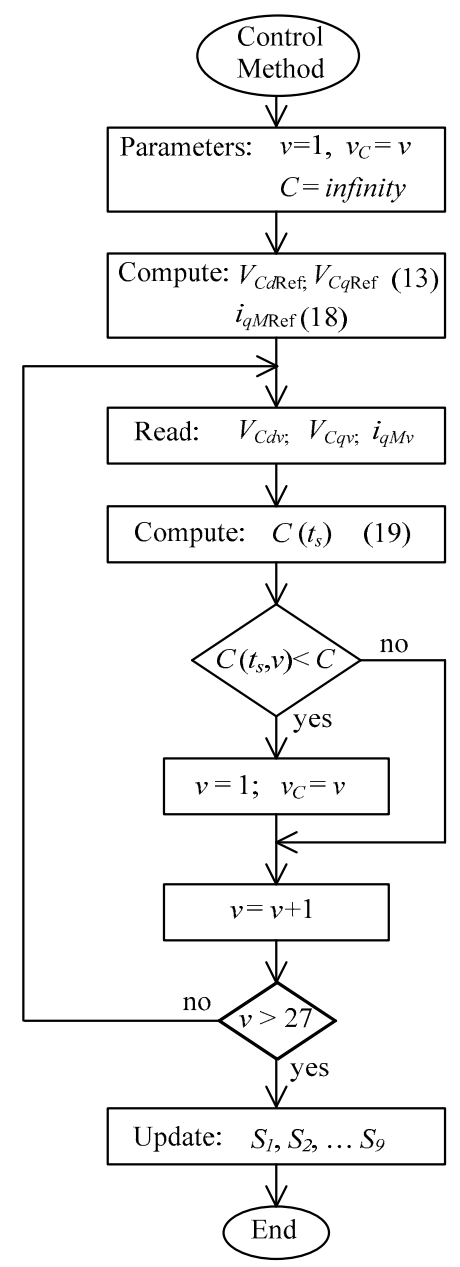

Figure 5. Flowchart of the control method proposed to compute $V_{C d \operatorname{Ref}}, V_{C q \operatorname{Ref}}(13)$ and $i_{q M \operatorname{Ref}}(18)$.

Relative to predictive controllers [19], the control process proposed here reduces the microprocessor computational effort.

\section{Simulation and Experimental Evaluation}

This section presents simulation and experimental results to evaluate the performance of the proposed control method. First, using detailed simulation models for the three-phase direct matrix converter, series and shunt transformers, sources, transmission lines, loads and real-time Lyapunov controller algorithm, the DMC-UPFC is simulated using the MATLAB/Simulink SimPowerSystems toolbox. Matrix converter semiconductors were simulated as SimPowerSystems switches with appropriate snubbers.

In order to validate the simulation results with experimental results, a low-power prototype DMC was built [23], using three semiconductor modules from DANFOSS, each one with six $1200 \mathrm{~V}, 25 \mathrm{~A}$ insulated-gate bipolar transistors (IGBT) with anti-parallel diodes, in a common collector arrangement, driven by optical isolated drives (TLP250). The second order input filter component values are: 
$l=4.2 \mathrm{mH}, C=6.6 \mu \mathrm{F}, r=25 \Omega$. This prototype was connected to the laboratory low-voltage network operating as a UPFC, (Figure 4) using three-phase transformers $T_{1}, T_{2}(2 \mathrm{kVA}$ transformers with voltage ratio $220 / 115 \mathrm{~V}$ and $66.5 / 66.5 \mathrm{~V}$, respectively). Voltage sensors were used to measure the voltages (LEM LV 25-P), while current sensors were used to measure the DMC currents (LEM LA25NP).

To carry out real-time control of the power in the transmission lines, a real-time DSP board (DS1103 model of dSPACE) with the proposed control algorithm was used to select the suitable vector at every sampling time. The DS1103 was able to execute the vector modulation, control algorithm, and output the 9 DMC bidirectional switch control signals at a sustained sampling time $\left(T_{s}\right)$ of $18 \mu \mathrm{s}$. This sampling time is suited to switching the DMC at frequencies around $5 \mathrm{kHz}$, but is not enough to guarantee safe commutation between the DMC bidirectional switches, as this requires much faster changing signals. Therefore, to ensure safe commutation, the four-step output current commutation strategy was used [18], implemented in a field-programmable gate array (FPGA) using a Xilinx (Virtex 5) board, as represented in Figure 4.

Experimental results were obtained considering that the input phase-to-phase DMC voltage equalled 120 VRMS; the load power equalled $1.5 \mathrm{~kW}(1 \mathrm{pu})$, the transmission lines 1 and 2 were emulated by inductances $L_{L 1}=12 \mathrm{mH}, L_{L 2}=15 \mathrm{mH}$ and series resistances $R_{L 1}=R_{L 2}=$ $0.2 \Omega$, respectively.

Also, experimental and simulation results for the $P$ and $Q$ power UPFC controller were obtained from the step response to changes in $P_{\text {Ref }}$ and $Q_{\text {Ref }}$ references $\left(\Delta P_{\operatorname{Ref}}\right.$ and $\Delta Q_{\text {Ref }}$, respectively). Figure $6 \mathrm{a}, \mathrm{b}$ show, respectively, simulation and experimental results for the proposed controller, considering $P$ and $Q$ power step responses to $\Delta P_{\text {Ref }}=+0.4 \mathrm{pu}$ and $\Delta Q_{\text {Ref }}=+0.2 \mathrm{pu}$, with initial reference values $P_{\text {Ref }}=0.4 \mathrm{pu}, Q_{\text {Ref }}=0.2 \mathrm{pu}$.

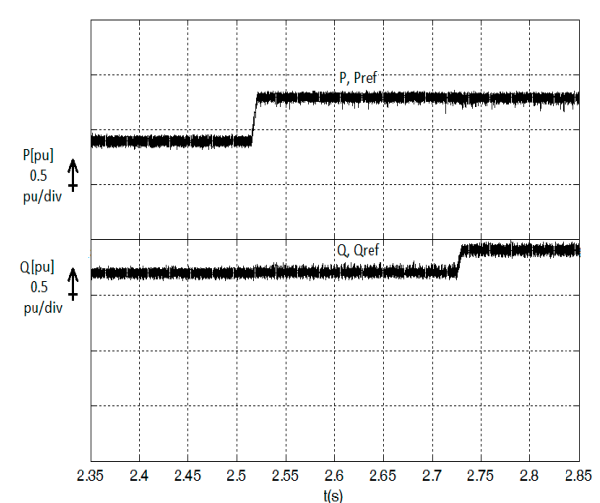

(a)

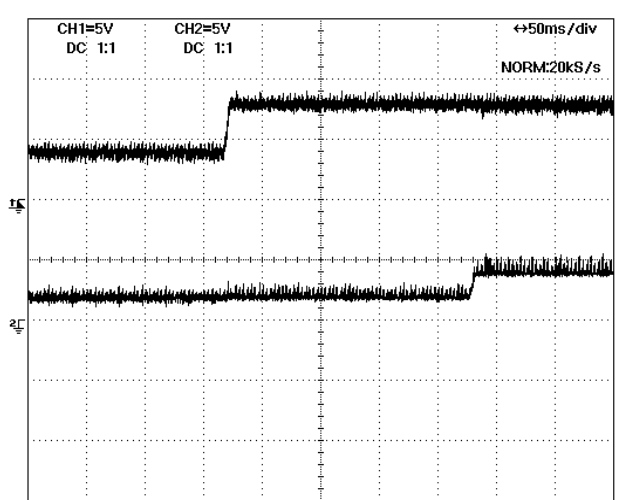

(b)

Figure 6. Active and reactive series power response for $P$ and $Q$ steps (first $\Delta P_{\text {Ref }}=+0.4$ pu and after $\Delta Q_{\text {Ref }}=+0.2 \mathrm{pu}$ ). (a) Simulation results; (b) Experimental results $(\mathrm{Ch} 1=\mathrm{Ch} 2=0.5 \mathrm{pu} / \mathrm{div})$.

Both results show clearly that there is no cross-coupling between active and reactive power, being both independently controlled, and showing a fast response with a small ripple in steady state. The results of Figure $7 \mathrm{a}, \mathrm{b}$ are simulation and experimental results, respectively, for the proposed control method, when the same initial conditions as in Figure 6 are retained, but with different time instants. Once again, these results prove the good performance of the power controller.

Figure $8 \mathrm{a}, \mathrm{b}$ show the simulation and experimental results, respectively, of the active and reactive powers, and also the line currents, considering $P$ and $Q$ power step responses to $\Delta P_{\text {Ref }}=+0.4$ pu and $\Delta Q_{\text {Ref }}=-0.2 \mathrm{pu}$, when initial reference values are $P_{\text {Ref }}=0.4 \mathrm{pu}, Q_{\text {Ref }}=0.2 \mathrm{pu}$. These results show no cross-coupling, steady-state errors below ripple errors, and fast response times for different changes of power references. Line currents are almost sinusoidal with small ripple content. 


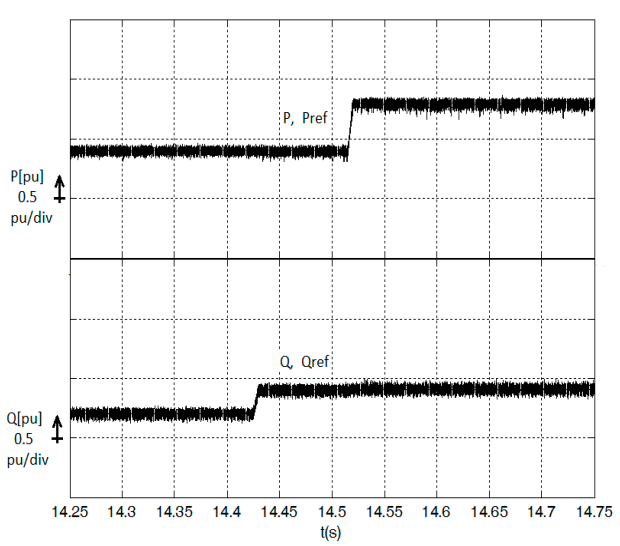

(a)

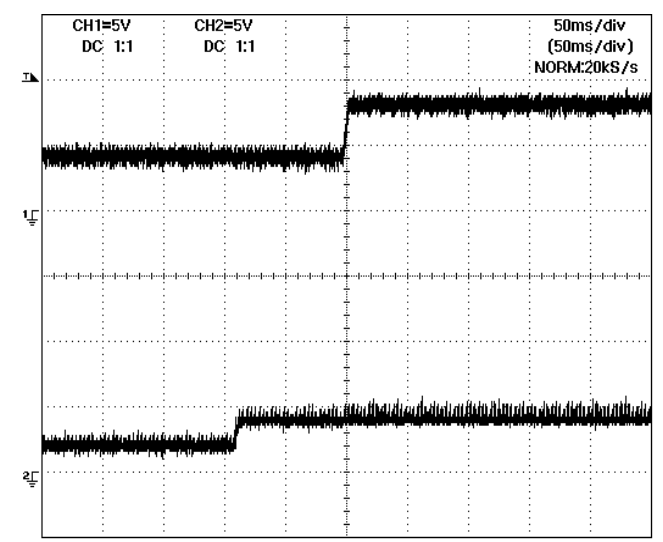

(b)

Figure 7. Active and reactive series power response for $P$ and $Q$ steps (first $\Delta Q_{\text {Ref }}=+0.2$ pu and after $\left.\Delta P_{\text {Ref }}=+0.4 \mathrm{pu}\right)$. (a) Simulation results; (b) Experimental results $(\mathrm{Ch} 1=\mathrm{Ch} 2=0.5 \mathrm{pu} / \mathrm{div})$.

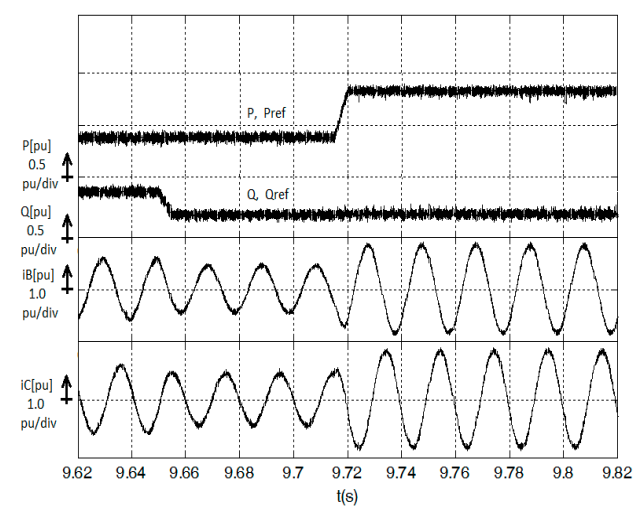

(a)

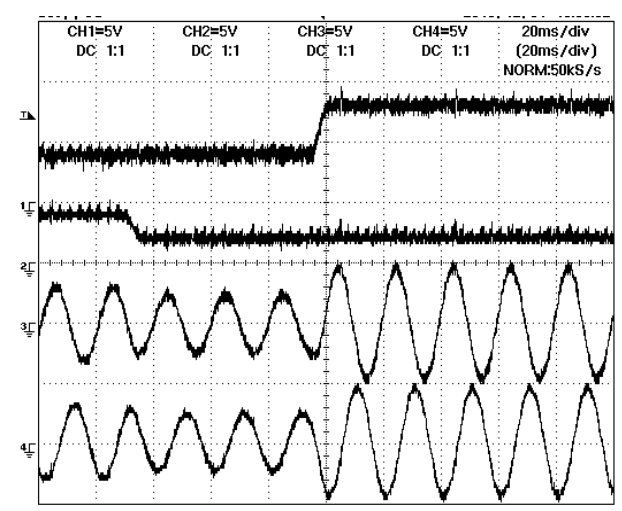

(b)

Figure 8. Active and reactive power response and line currents for a $P$ and $Q$ step $\Delta P_{\text {Ref }}=+0.4$ pu and $\Delta Q_{\text {Ref }}=+0.2 \mathrm{pu}$ ). (a) Simulation Results; (b) Experimental results, Ch1 $=\mathrm{Ch} 2=0.5 \mathrm{pu} / \mathrm{div}$ ( $P$ Series and $Q$ Series) and $\mathrm{Ch} 3=\mathrm{Ch} 4=1.0 \mathrm{pu} / \mathrm{div}$ (iB and $\mathrm{iC}$ ).

Results of Figures $8 \mathrm{~b}$ and 9a show line and input direct matrix converter currents in steady-state, for $P_{\text {Ref }}=0.4 \mathrm{pu}, Q_{\text {Ref }}=0.2 \mathrm{pu}$. Line currents are almost sinusoidal with small ripple content, while matrix currents shows some ripple content as usual in DMC [15].

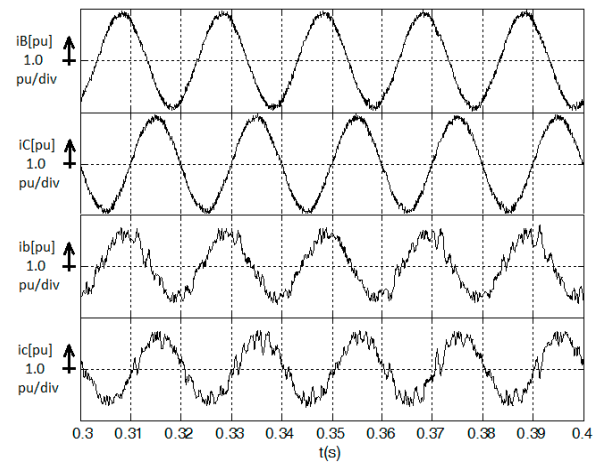

(a)

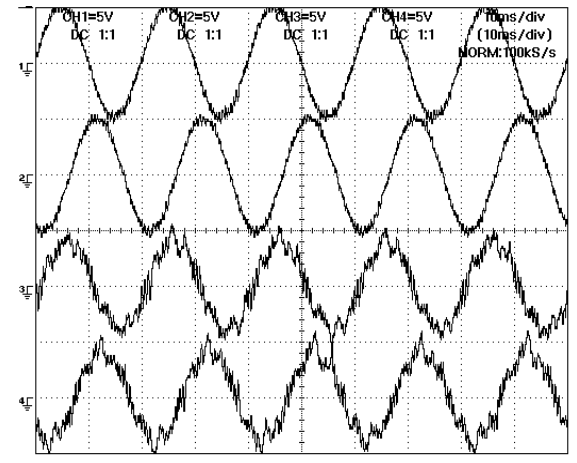

(b)

Figure 9. Line currents $(\mathrm{iB}, \mathrm{iC})$ and input matrix converter currents (ib, ic) for $\Delta P_{\mathrm{Ref}}=+0.4 \mathrm{pu}$ and $\Delta Q_{\text {Ref }}=+0.2$ pu: (a) Simulation results; (b) Experimental results $(\mathrm{Ch} 1=\mathrm{Ch} 2=\mathrm{Ch} 3=\mathrm{Ch} 4=1.0 \mathrm{pu} / \mathrm{div})$. 
The experimental power spectral density of transmission line converter current (Figure 10) shows that the main harmonics are nearly $35 \mathrm{~dB}$ below the $50-\mathrm{Hz}$ fundamental.

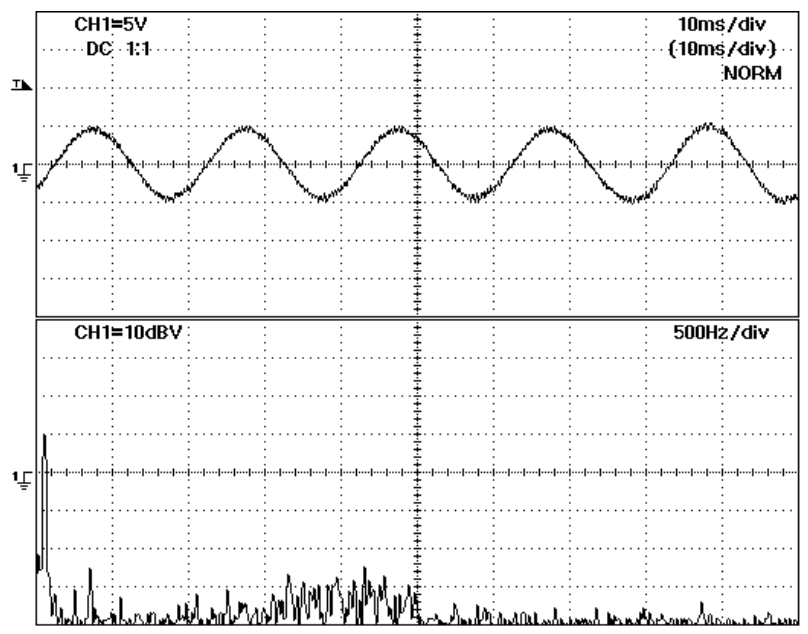

Figure 10. Power spectral density of line current (iB) $10 \mathrm{dBV} /$ div.

Figure 11a,b show, respectively, the harmonic spectrum of the line current and load voltage. These quantities present a low harmonic content (THD less than $5 \%$ ) of $4.86 \%$ and $4.53 \%$, respectively, which compares favourably with the improved methods proposed in [24] to enhance power quality in matrix converters (the THD of input currents is higher than $6.29 \%$ in [24]).

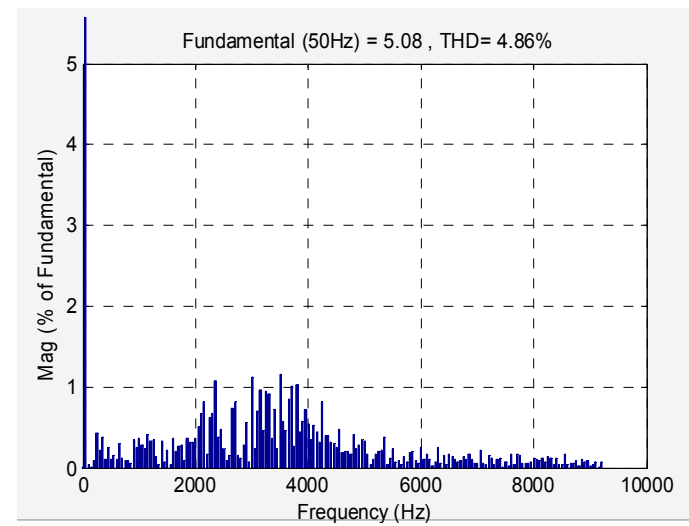

(a)

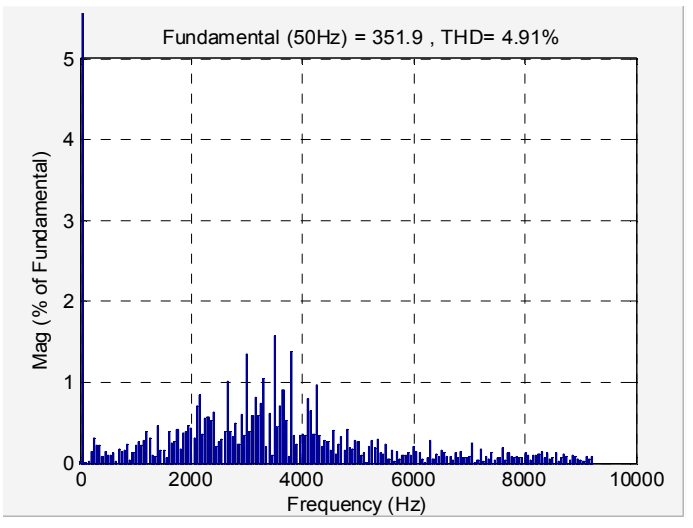

(b)

Figure 11. Harmonic content of the line currents (a) and of the load voltages (b).

Compared to linear [24], sliding-mode [15], and predictive [20] controllers, the Lyapunov controlled matrix-based UPFC presents the lowest THD of currents, even lower than linear controllers; while for cross-coupling and response times, they present better results, as do sliding-mode and predictive controllers. Concerning steady-state errors, all controllers theoretically show no steady-state errors, while the Lyapunov controller's asymptotic stability guarantees that the controller will enforce an exponentially stable dynamic, tending to zero error, which is not guaranteed by predictive controllers.

Simulation and experimental results show that $P$ and $Q$ power flow can be effectively controlled using the DMC-based UPFC and the proposed power control method.

A DMC-based UPFC was implemented in the laboratory to verify the proposed power controller, as shown in Figure 12. 


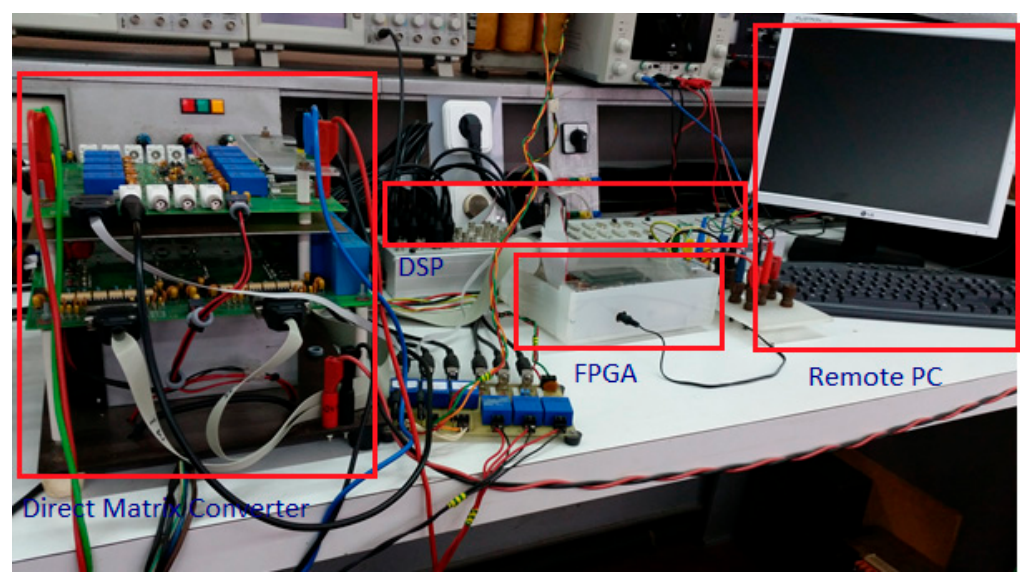

Figure 12. The experimental setup using the DMC based UPFC.

\section{Conclusions}

This paper designs a new real-time space-vector control, based on the Lyapunov stability direct approach, for active and reactive power flow using direct matrix converters connected to the power transmission line operating as Unified Power Flow Controllers. This controller guarantees stability of the power system and improves the power quality by optimizing the space-vector error cost functional.

The presented simulation and experimental results show that active and reactive power flow can be advantageously controlled using the proposed control method. Results show steady-state errors below ripple errors, no cross-coupling, insensitivity to non-modeled dynamics, fast response times and low THD in output currents (less than $5 \%$ ).

Acknowledgments: This work was supported in part by national funds through Fundação para a Ciência e Tecnologia (FCT) with reference UID/CEC/50021/2013.

Author Contributions: José Fernando Silva and Aranzazu Delgado Martin conceived the theory; Joaquim Monteiro designed and performed the experiments; Joaquim Monteiro and José Fernando Silva analyzed the data; Joaquim Monteiro, Sónia Pinto, Aranzazu Delgado Martin, and José Fernando Silva wrote the paper.

Conflicts of Interest: The authors declare no conflicts of interest.

\section{References}

1. Gyugyi, L. Unified Power Flow Controller (UPFC). In Advanced Solutions in Power Systems: HVDC, FACTS, and Artificial Intelligence: HVDC, FACTS, and Artificial Intelligence; Eremia, M., Liu, C.-C., Edris, A.-A., Eds.; John Wiley \& Sons, Inc.: Hoboken, NJ, USA, 2016.

2. Hingorani, N.; Gyugyi, L. Understanding FACTS: Concepts and Technology of Flexible AC Transmission Systems; Wiley-IEEE Press: New York, NY, USA, 2000.

3. Moranchel, M.; Bueno, E.; Sanz, I.; Rodríguez, F.J. New Approaches to Circulating Current Controllers for Modular Multilevel Converters. Energies 2017, 10, 86. [CrossRef]

4. Gyugyi, L.; Schauder, C.; Williams, S.; Rietman, T.; Torgerson, D.; Edris, A. The Unified Power Flow Controller: A New Approach to Power Transmission Control. IEEE Trans. Power Deliv. 1995, 10, 1085-1097. [CrossRef]

5. Liu, L.; Zhu, P.; Kang, Y.; Chen, J. Power-Flow Control Performance Analysis of a Unified Power-Flow Controller in a Novel Control Scheme. IEEE Trans. Power Deliv. 2007, 22, 1613-1619. [CrossRef]

6. Chivite-Zabalza, J.; Izurza-Moreno, P.; Madariaga, D.; Calvo, G.; Rodriguez, M.A. Voltage Balancing control in 3-Level Neutral-Point Clamped Inverters Using Triangular Carrier PWM Modulation for FACTS Applications. IEEE Trans. Power Electron. 2013, 28, 4473-4484. [CrossRef]

7. Chivite-Zabalza, J.; Rodriguez Vidal, M.A.; Izurza-Moreno, P.; Calvo, G.; Madariaga, D. A Large Power, Low-Switching-Frequency Voltage Source Converter for FACTS Applications with Low Effects on the Transmission Line. IEEE Trans. Power Electron. 2012, 27, 4868-4879. [CrossRef] 
8. Peng, F.Z.; Liu, Y.; Yang, S.; Zhang, S.; Gunasekaran, D.; Karki, U. Transformer-Less Unified Power-Flow Controller Using the Cascade Multilevel Inverter. IEEE Trans. Power Electron. 2016, 31, 5461-5472. [CrossRef]

9. Sayed, M.A.; Takeshita, T. All Nodes Voltage Regulation and Line Loss Minimization in Loop Distribution Systems Using UPFC. IEEE Trans. Power Electron. 2011, 26, 1694-1703. [CrossRef]

10. Geethalakshmi, B.; Dananjayan, P. Investigation of Performance of UPFC without DC Link Capacitor. Electr. Power Energy Res. 2008, 78, 736-746. [CrossRef]

11. Strzelecki, R.; Noculak, A.; Tunia, H.; Sozanski, K. UPFC with Matrix Converter. In Proceedings of the EPE'01 Conference, Graz, Austria, 27-29 August 2001.

12. Monteiro, J.; Silva, J.; Pinto, S.; Palma, J. Unified Power Flow Controllers without DC Bus: Designing Controllers for the Matrix Converter Solution. In Proceedings of the International Conference on Electrical Engineering (CEE'05), Coimbra, Portugal, 10-12 October 2005.

13. Ma, T. P-Q Decoupled Control Schemes Using Fuzzy Neural Networks for the Unified Power Flow Controller. Electr. Power Energy Syst. 2007, 29, 748. [CrossRef]

14. Monteiro, J.; Silva, J.; Pinto, S.; Palma, J. Matrix Converter-Based Unified Power-Flow Controllers: Advanced Direct Power Control Method. IEEE Trans. Power Deliv. 2011, 26, 420-430. [CrossRef]

15. Monteiro, J.; Silva, J.; Pinto, S.; Palma, J. Linear and sliding-mode control design for matrix converter-based unified power flow controllers. IEEE Trans. Power Electron. 2014, 29, 3357-3367. [CrossRef]

16. Dasgupta, A.; Tripathy, P.; Sensarma, P. Matrix Converter as UPFC for Transmission Line Compensation. In Proceedings of the 7th International Conference on Power Electronics, Daegu, Korea, 22-26 October 2007; pp. 1050-1055.

17. Empringham, L.; Kolar, J.W.; Rodriguez, J.; Wheeler, P.W.; Clare, J.C. Technological Issues and Industrial Application of Matrix Converters: A Review. IEEE Trans Ind. Electron. 2013, 60, 4260-4271. [CrossRef]

18. Szcześniak, P.; Kaniewski, J.; Jarnut, M. AC-AC power electronic converters without DC energy storage: A review. Energy Convers. Manag. 2015, 92, 483-497. [CrossRef]

19. Silva, J.F.; Pinto, S.F. Advanced Control of Switching Power Converters. In Power Electronics Handbook, 3rd ed.; Rashid, M.H., Ed.; Elsevier: Burlington, NJ, USA, 2011; pp. 1037-1114.

20. Barros, J.; Silva, J.; Jesus, E.G.A. Fast-Predictive Optimal Control of NPC Multilevel Converters. IEEE Trans. Ind. Electron. 2013, 60, 619-627. [CrossRef]

21. Akagi, H.; Kanazawa, Y.; Nabae, A. Instantaneous Reactive Power Compensators Comprising Switching Devices without Energy Storage Components. IEEE Trans. Ind. Appl. 1984, IA-20, 625-630. [CrossRef]

22. Khalil, H.K. Nonlinear Systems, 3rd ed.; Prentice Hall: Upper Saddle River, NJ, USA, 2002.

23. Pinto, S.; Silva, J. Sliding Mode Direct Control of Matrix Converters. IET Electr. Power Appl. 2007, 1, 439-448. [CrossRef]

24. Shi, T.; Yan, Y.; An, H.; Li, M.; Xia, C. Improved Double Line Voltage Synthesis Strategies of Matrix Converter for Input/Output Quality Enhancement. IEEE Trans. Ind. Electron. 2013, 60, 3034-3046. [CrossRef] 